\title{
Research of Risk Evaluation Model for CBM Development Based on Multi-Information Fusion
}

\author{
Yongchang Zhang ${ }^{1,2}$ and Yongguo Yang ${ }^{*}, 3$ \\ ${ }^{1}$ School of Resource and Earth Science, Key Laboratory of CBM Resources and Reservoir Formation Process of \\ Ministry of Education, China University of Mining and Technology, Xuzhou 221116, Jiangsu, China \\ ${ }^{2}$ Jiangsu Jianzhu Institute, Xuzhou 221116, Jiangsu, China \\ ${ }^{3}$ School of Resource and Earth Science, China University of Mining and Technology, Xuzhou 221116, Jiangsu, China
}

\begin{abstract}
CBM development is a major concern in national energy projects. With high investment, high risks and high yield, CBM enables many investors generate the project plans while expressing concerns at the same time regarding the risks. Focusing on the development of risk assessment model in CBM development and applications, this paper proposes the CBM development risk assessment model of multi-information fusion, describing in detail the composite structure and application methods of the model, and eventually proves the model feasibility and significance by practical instances.
\end{abstract}

Keywords: Exploitation of CBM, multi-source information, risk assessment model.

\section{INTRODUCTION}

Coalbed methane (CBM) as one of the most widely used energies in our country has good prospects for commercial development. More and more CBM resources are put into development while causing a lot of issues because of its high risk and relatively high total investment, thus making investors feel worried and suppressing the industrial development [1-4]. Therefore, it is very necessary to research on the risk assessment model for CBM development, so as to provide references for investors to invest in the CBM industry, reasonably avoiding risk and achieving maximum benefits.

However, since in the actual risk assessment process, some of the underlying data does not provide effective statistics, thereby leading to ineffective usage of the conventional risk assessment model. In this case, multisource information fusion is introduced to propose a new prediction method, which ensures the prediction accuracy while realizing dynamic prediction of gas emission quantity in combination with the actual case of gas emission in the excavation working faces [5-7]. This makes prediction more targeted, time-valid and reliable, in turn meeting the demand for high yield and efficiency mine construction in modern times.

Based on this, from the perspective of multi-source information fusion, this paper specifically studies the risk assessment model for CBM development, in order to compensate for deficiencies in the conventional risk assessment model.

*Address correspondence to this author at the School of Resource and Earth Science, China University of Mining and Technology, Xuzhou 221116, Jiangsu, China; E-mail: ygyang88@cumt.edu.cn

\section{PRINCIPLE OF RISK ASSESSMENT OF CBM DEVELOPMENT BY MULTI-SOURCE INFORMATION FUSION}

Multi-source information fusion (MSIF) refers to the technology that combines and merges multiple sources of information or data in order to obtain a unified result. Information fusion refers to usage of homogeneous or heterogeneous information obtained from multiple sources from different space or time for combination or integration at different abstract levels, to obtain a more complete, more accurate and more reliable information or inference of relevant entities, relationships or events [8-10]. Information fusion can generally be divided into: decision-level fusion, feature-level fusion and data-level integration, which extract feature information from raw data and fuse local decisionmaking information acquired from further assessment or reasoning. Data-level and feature-level fusion belong to a low-level fusion, while the high level--decision-level fusion-involves awareness and assessment of the situation, impact assessment, optimization of the fusion process and so on.

The low-level integration predicted by gas emission based on multi-source information fusion includes coal seam characteristics information, gas content data, mining information, gas emission data, etc. The high-level integration refers to the decision-level fusion combining the established gas emission prediction model with the traditional gas emission prediction method.

As can be seen from the above analysis (Fig. 1), risk assessment mathematical model based on multi-source fusion has broad applicability. Whether in the mine design stage lacking gas emission quantity measured data or in the mine production phase, when predicting the gas emission in the deep unexploited mining area, the multi-source fusion 


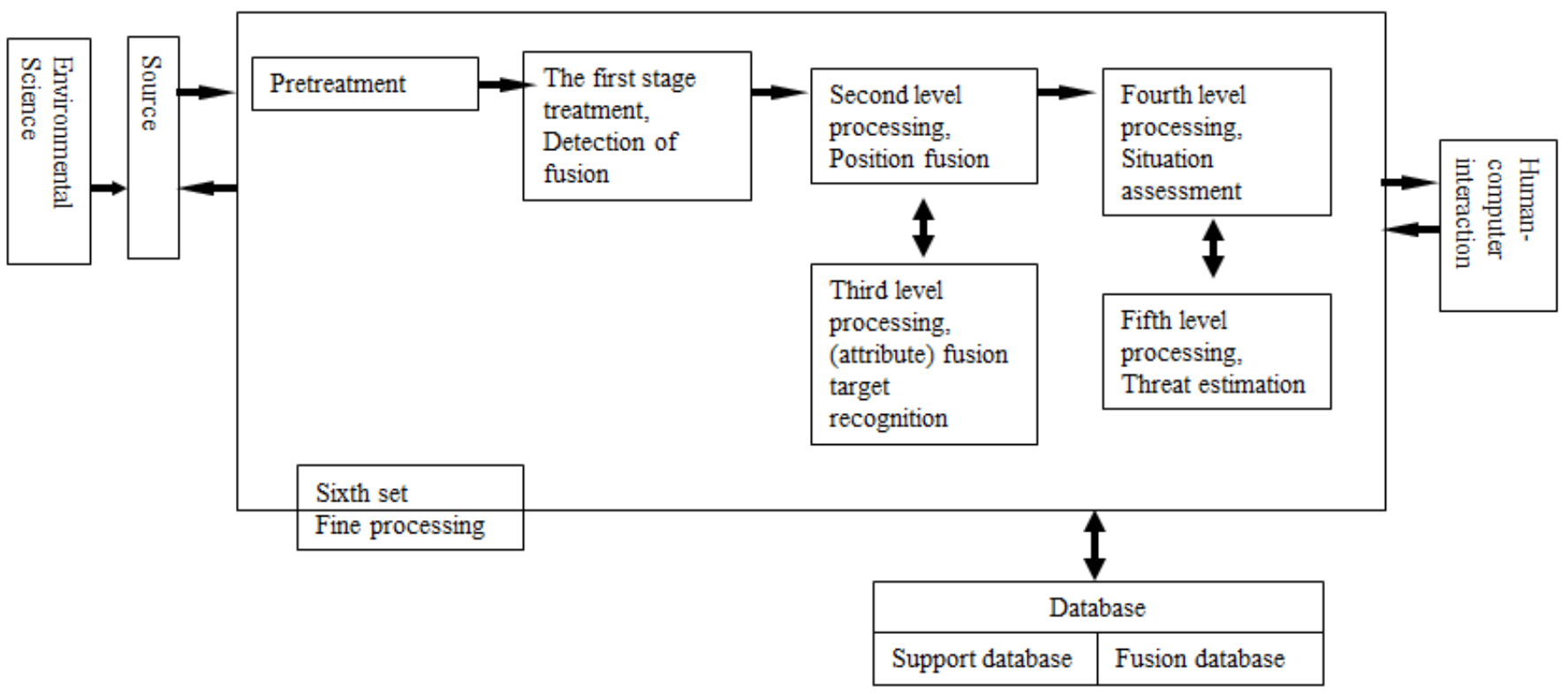

Fig. (1). Information fusion system six-level functional classification model.

risk assessment model can take advantage of the measured

data, comprehensively considering a variety of factors like geological conditions and mining depth, and providing reliable risk evaluation results.

\section{MULTI-SOURCE INFORMATION FUSION PROCEDURE}

\subsection{Acquisition of Multi-Source Information}

For establishing the CBM development risk assessment model, more data is required. For example, the premise of gas emission forecast is to obtain the gas parameters, and there are various methods of acquiring the gas parameters, mainly including method for measuring a coal seam gas content in an underground coal mine, modification method for determining coefficients of gas content in geological exploration, gas desorption index of drill cuttings and gas emission parameter inversion method, among others. However, the above four methods make use of conditions and estimate the pros and cons, and these methods should be effectively integrated.

1) It is currently recognized that the gas content data measured in underground coal mine are the most accurate method for measuring coal seam gas content. This method has gone through continuous research, and has been improved and perfected in terms of the sampling process, the loss calculation model, and the gas parameter measurement process. It can meet engineering applications, and has developed a national standard "Coal Seam Gas Content Underground Direct Measurement" (GB/T 232502009). However, this method can only be used in the existing development roadways, but not in unexploited areas.

2) Geological prospecting gas content data are mainly used in the overall grasp of gas content area in unexploited areas. The method is restricted by the overall technological level of gas parameter measuring during the geological prospecting, so that there is great global error. Before using, the geological prospecting data need to be corrected, and the common method in the country is the coefficient method, which compares the gas parameter measured in the exploited area and the geological exploration drilling data in the exploited area and obtains the correction coefficient, then uses the coefficient in the correction of gas content data of geological exploration drilling in the entire mine field.

3) It is necessary to predict whether there is coal and gas outburst risk in front of the excavation working face before mining and driving in the outburst mines, and one of the main indicators that predict outburst danger is the gas desorption index of drill cuttings, namely $\mathrm{K} 1$ or $\Delta \mathrm{h} 2$. In China's "Research of Determining Method for Sensitive Critical Index in Working Face Prediction" in the "Ninth Five" scientific and technological project, it is found that there is an association between $\mathrm{K} 1(\Delta \mathrm{h} 2)$ and the gas pressure $\mathrm{p}$ : $\mathrm{K} 1=\mathrm{ApB}$ (1).

where $\mathrm{K} 1$ is the gas desorption index of drill cuttings; $\mathrm{p}$ is the gas pressure, $\mathrm{MPa} ; \mathrm{A}$ and $\mathrm{B}$ are coefficients to be determined; the coal samples are taken in field sampling and determined in a laboratory.

As per this method, by inverting the single gas desorption index of drill cuttings, the determined coal seam gas pressure has a relatively large error, but because in the field, massive explorations have been conducted to determine the K1 value, coal seam gas pressure based on the statistical method can not only discover the general laws from the trend, but also gradually approach the desired output from huge amounts of data.

4) It is also an effective method to use the gas concentration data from real-time monitoring by 
safety monitoring system, combined with mining schedule, volume of air supply, and tunnel crosssection parameters, to invert the coal seam gas content in front of the working face. There is also a lot of research at home and abroad. In the $11^{\text {th }}$ FiveYear Plan, Research Institute Of Coal Science And Industry Group in Chongqing supported the establishment of the coal seam gas content analysis model predicting through gas emission dynamics by means of the basic theory research project.

where $\mathrm{W}$ is the gas content inversion result (unit: $\left.\mathrm{m}^{3} / \mathrm{t}\right) ; X_{i, 1}$ and $X_{i, 2}$ are the means of gas emission monitoring data shifts for underground drill and nondrill operations; $\% ; X_{i, 30 \mathrm{~min}, 1}, X_{\mathrm{i}, 30 \mathrm{~min}, 2}$ are the mininal shift values for 30 min underground drill and non-drill operations. \%; $\mathrm{M} n$ are the coal amounts of shift $\mathrm{i}-\mathrm{n}$ to shift $\mathrm{i}$ in the coalface (unit: $\mathrm{t}$ ); $Q_{f}$ is roadway air volume (unit: $\mathrm{m}^{3} / \mathrm{min}$ ); $\mathrm{T}$ is time ( $\mathrm{min}$ ); $\alpha, \beta, p_{1}$ and $p_{2}$ are coefficients; $V$ is the roadway driving speed, $\mathrm{t} / \mathrm{d}$.

$$
\begin{aligned}
& \mathrm{W}=\frac{\sum_{\mathrm{j} i \mathrm{i}-\mathrm{n}}^{\mathrm{i}}\left\{\left[\mathrm{X}_{\mathrm{i}, 1}-(1-\beta) \times \mathrm{X}_{\mathrm{i}, 30 \text { min }, 1}\right] \times \alpha \times \mathrm{T} \times \mathrm{Q}_{\mathrm{f}}\right\}}{\mathrm{M}_{\mathrm{n}}} \\
& +\frac{\sum_{\mathrm{j}=\mathrm{i}-\mathrm{n}}^{\mathrm{i}}\left\{\left[\mathrm{X}_{\mathrm{i}, 2}-(1-\beta) \times \mathrm{X}_{\mathrm{i}, 30 \min , 2}\right] \times \alpha \times \mathrm{T} \times \mathrm{Q}_{\mathrm{f}}\right\}}{\mathrm{M}_{\mathrm{n}}} \\
& \mathrm{p}_{1} \cdot \ln (\mathrm{V})+\mathrm{p}_{2}
\end{aligned}
$$

\subsection{Information Source Data Processing Method}

Gas emission prediction is the key to accurately grasp the coal seam gas parameters. However, different regions are subjected to a greater impact from coal seam sedimentary evolution and late structural movement, and the objective conditions have restricted different regions to adopt a uniform approach for gas emission rate forecast, and it is technically not feasible. Therefore, before processing data, first different geological tectonic units should be divided and it would be relatively objective to process data in different tectonic units.

Since gas emission prediction activities are carried out in unexplored areas, and in four kinds of data sources, only geological exploration data can overall grasp the gas parameters in the whole range of the well field. Therefore, the geological prospecting data should serve as a basis. However, the geological prospecting is confined to process conditions and exhibits large overall errors. The gas content data in underground testing is the most accurate and it is feasible to compare the gas content data in underground testing and the geological prospecting gas content data around the measured points. The correction coefficient for the point is calculated and acquired by the correction factor of a number of points. The regression method is used to obtain a reasonable correction factor, and then the corrected geological prospecting data is the gas content data base of the whole well field.

The gas content data in the geological prospecting period is less and also not representative, and it is necessary to take advantage of the gas desorption index of drill cuttings and the gas desorption index around the exploitation area to invert the gas content data for supplement. These two kinds of inverting gas content data need to be applied in the statistical basis. Specifically, first based on the statistic theoretical analysis, the distribution law of the gas content data is inverted in the region. With this law, the gas content is computed in the geological exploration area and based on this, the gas content is inverted and establishes the regional gas distribution law as per the modified gas content regional distribution law.

\subsection{Mathematical Model Coupling With Multi-Source Information}

According to the regional distribution law of coal seam gas content, the common different-source forecast method is employed to build the gas emission prediction model. This model has changed the previous mathematical models that are constructed based on individual gas content points and improved the accuracy and reliability of the model, but it also lacks merit of the mine statistical method, and therefore further optimization is also needed in the mathematical model in order to grasp its objectivity. The coupling method of specific models generally is adopted with the coefficient method according to engineering needs. The method has two major advantages. On one hand, it can verify the accuracy of the entire process according to the coefficient ratio; on the other hand, it is relatively simple in engineering applications and actually absorbs the advantages of two kinds of methods. Coupling contains three steps. The first is to use the different-source forecast method to build the model $\mathrm{Q}=$ $\mathrm{f}(\mathrm{W})$; secondly, the model calculation results are compared with the actual statistics of the gas emission data in the exploited area to obtain the comparison coefficient; thirdly, it modifies the different-source forecast method, and obtains a new mathematical model $\mathrm{Q}^{\prime}=\mathrm{f}\left(\mathrm{W}^{\prime}\right)$, to further improve the predictive accuracy of the results.

\section{APPLICATION EXAMPLES}

The multi-source information fusion is applied to evaluate the gas emission risk in eight mining areas of Anhui Luling Mine, and the results are shown in Table 1. In accordance with the production condition, the gas content multi-source information is acquired, and the gas emission quantity mathematical model $\mathrm{Q}=1.7375 \mathrm{~W}+0.6633$ is constructed based on the different-source forecast method. Further, according to the actual gas emission data, the CBM development model is modified and a new mathematical model is obtained: $\mathrm{Q}^{\prime}=1.788 \mathrm{~W}^{\prime}+0.14$.

Table 1. Absolute gas emission prediction results of eight mining areas.

\begin{tabular}{|c|c|c|}
\hline $\begin{array}{c}\text { Coal Seam } \\
\text { Floor Level/m }\end{array}$ & $\begin{array}{c}\text { Relative Gas } \\
\text { Emission Forecast }\end{array}$ & $\begin{array}{c}\text { Relative } \\
\text { Error/\% }\end{array}$ \\
\hline \hline-400 & 19.65 & 8.29 \\
\hline-450 & 20.32 & 6.27 \\
\hline-500 & 26.09 & 3.53 \\
\hline
\end{tabular}


As can be seen from Table 1, when comparing the amount of gas emission statistics in the stope face and the predictive value of gas emission amount prediction model, the relative error averages about $7 \%$, and the accuracy rate is higher than $80 \%$, which is required in the field for prevention and cure of gas hazards. The risk assessment model for coal seam gas content is accurate.

\section{CONCLUSION}

Multi-source information fusion theory and technology are superior in the risk assessment of CBM development. Based on the theoretical advantages of the multi-source information fusion technology, the information regarding the development risk can be acquired from a plurality of information sources, such as coal seam characteristics, gas content, mining information, gas emission and other lowlevel data fusion, and the single source problem of the current forecast methods can be tackled. At the same time, the decision-level fusion can be achieved by fusing gas emission prediction model and the traditional gas emission prediction method, which has great significance in improvement of the accuracy and reliability of the risk assessment of CBM development.

\section{CONFLICT OF INTEREST}

The authors confirm that this article content has no conflict of interest.

\section{ACKNOWLEDGEMENTS}

This study was supported by the Key Program of the National Natural Science Foundation of China (Grant No. 41372342, Grant No. 40972207), the Key Special Project of the National Science and Technology of China (Grant No. 2011ZX05034-005), Philosophy and Social Science Foundation of Colleges in Jiangsu Province (Grant No.
2014SJD475), and the Science Foundation of Jiangsu Institute of Architecture (Grant No. JYA14-26).

\section{REFERENCES}

[1] Dong, Z.; Holditch, S.A.; Ayers, W.B.; Lee, W.J. Probabilistic Estimate of Global Coalbed Methane Recoverable Resources. In: SPE Unconventional Resources Conference. Society of Petroleum Engineers, 2014

[2] Pashin, J.C.; McIntyre-Redden, M.R.; Mann, S.D.; KopaskaMerkel, D.C.; Varonka, M.; Orem, W. Relationships between water and gas chemistry in mature coalbed methane reservoirs of the Black Warrior Basin. Int. J. Coal Geol., 2014, 126, 92-105.

[3] Gan, T.; Puspitasari, R.; Loth, M.J.; Pallikathekathil Z.J.; Luft, J. Core Analysis Challenges and Solutions in Characterizing Coal Mechanical Properties for Successful Drilling and Completion of Horizontal Coal Bed Methane Well. In: International Petroleum Technology Conference. International Petroleum Technology Conference, 2014.

[4] Shi, J.; Pan, Z.; Durucan, S. Analytical models for coal permeability changes during coalbed methane recovery: Model comparison and performance evaluation. Int. J. Coal Geol., 2014, 136, 17-24.

[5] Cai, B.; Liu, Y.; Fan, Q.; Zhang, Y.; Liu, Z.; Yu, S.; Ji, R. Multisource information fusion based fault diagnosis of ground-source heat pump using Bayesian network. Appl. Energy, 2014, 114, 1-9.

[6] Zhou, X.; Jiang P. Variation source identification for deep hole boring process of cutting-hard workpiece based on multi-source information fusion using evidence theory. J. Intell. Manufact., 2014, 1-16.

[7] Xie, Y.; Yi, S.; Tanga, Z.; Pan, D. Uncertainty multi-source information fusion for intelligent flood risk analysis based on random set theory. Int. J. Computat. Intell. Syst., 2012, 5(5), 975984.

[8] Cui, P.; Zhang, Z.; Cai, W.; Huang H.Z.; Li Y.F.; Wang H. Fatigue lifetime assessment of aircraft engine disc based on multi-source information fusion. In: International Conference on Quality, Reliability, Risk, Maintenance, and Safety Engineering (QR2MSE), 2013.

[9] Wan, J.; Ji, J.; Wang, W.; Zhang, L. Multi-source Information Fusion for Video Detection in Highway. Mod. Transportat., 2014, 3(3), 49-55.

[10] He, J.; Tian, S.; Yang X. Research of fault line selection method for small current grounding system based on multi-source information fusion. Gongkuang Zidonghua-Ind. Mine Automat., 2013, 39(3), 56-60.

This is an open access article licensed under the terms of the Creative Commons Attribution Non-Commercial License (http://creativecommons.org/licenses/ by-nc/4.0/) which permits unrestricted, non-commercial use, distribution and reproduction in any medium, provided the work is properly cited. 